\title{
Experiencia de extrañamiento \\ en los desplazamientos migratorios: \\ la migración como trayecto de subjetivación
}

\author{
Antonia Lara \\ Fernanda Stang \\ Universidad Católica Silva Henríquez. Centro de Investigación en Ciencias Sociales \\ y Juventud (CISJU) \\ alara@ucsh.cl; fstang@ucsh.cl
}

\section{Resumen}

A partir de dos estudios diferentes sobre procesos migratorios internacionales dentro de América Latina (de carácter sur-sur), que tuvieron como destino la ciudad de Santiago (Chile), reflexionamos en torno a la experiencia de extrañamiento respecto a sí mismo y a los otros en estos desplazamientos migratorios, entendida como una interpelación que impulsa procesos de subjetivación vinculados a la condición de extranjeridad, que emergió como hallazgo en ambas investigaciones. La exploración de esta idea se realiza a partir de relatos de migración construidos mediante el trabajo de campo de ambos estudios, de carácter cualitativo. El primero recurrió a la construcción de relatos de migración de mujeres dominicanas, mientras que el segundo utilizó relatos de vida de migrantes peruanos y colombianos con subjetivaciones sexogenéricas no heteronormativas. El objetivo de este escrito es describir esas experiencias para delinear esta noción de extrañamiento en los procesos migratorios y poner atención en los impactos subjetivos que esta experiencia imprime en el migrante. El recorrido permite concluir que este se enfrenta a la experiencia de descalce y extrañamiento de sí, que deviene de la imagen de alteridad que le devuelve la sociedad receptora. Ante esto, reacciona haciendo incorporaciones, resistencias o ajustes a sus maneras de hacer, muchas veces de modo situacional y estratégico para el logro de sus fines, en los que no necesariamente se encuentra del todo identificado/a. Estas experiencias impulsan procesos de reflexión acerca de su imagen identitaria que abren nuevas posiciones enunciativas y transformaciones en los procesos de subjetivación.

Palabras clave: identificaciones culturales; frontera; extranjeridad; alteridad; migraciones sur-sur; extrañamiento; subjetivación 
Abstract. The experience of estrangement in migratory movements: migration as a journey of subjectivation

Based on the findings of two different studies on international migration processes within Latin America (south-south), which had as their destination the city of Santiago (Chile), we reflect on the experience of estrangement from oneself and from each other. The others in these migratory movements, understanding it as an interpellation that promotes processes of subjectivation linked to the condition of foreignness, which emerged as a finding in both investigations. The exploration of this idea is carried out from migration stories constructed through fieldwork in both studies, of a qualitative nature: the first of them recurred to the construction of migration stories of Dominican women, while the second used stories of Life of Peruvian and Colombian migrants with non-heteronormative sex-generic subjectivations. The objective of this paper is to describe those experiences to delineate this notion of estrangement in migratory processes, paying attention to the subjective impacts that this experience impresses on the migrant. The tour allows us to conclude that he faces the experience of what does not fit and the estrangement from oneself, which comes from the image of otherness that the host society returns to him. Faced with this, he reacts by making additions, resistances or adjustments to his ways of doing, often in a situational and strategic way to achieve his goals, in which he is not necessarily fully identified. These experiences promote processes of reflection about their identity image that open up new enunciative positions and transformations in the processes of subjectivation.

Keywords: cultural identifications; border; foreignness; otherness; south-south migrations; estrangement; subjectivation

\section{Sumario}

\section{Introducción}

2. Fronteras y extrañamiento

3. Algunas aproximaciones al extrañamiento: etnografía y psicoanálisis

4. Experiencia de lo ominoso: la inquietante extrañeza de lo extranjero en nosotros mismos
5. Relatos: escenas de extrañamiento

6. Extrañamientos situacionales, constricciones y liberaciones

7. Conclusiones

Referencias bibliográficas

\section{Introducción}

En este artículo nos proponemos reflexionar en torno al lugar y la función de la experiencia de extrañamiento, como interpelación que impulsa (o es motor de) procesos de subjetivación vinculados a la condición de extranjeridad. Esta noción de extrañamiento emergió de dos investigaciones distintas, y no vinculadas en principio, que abordaron diferentes aspectos de los procesos de subjetivación en migrantes latinoamericana/os residentes en Chile. ${ }^{1} \mathrm{La}$ exploración

1. Se trata de dos investigaciones doctorales: una titulada «Subjetividades en tránsito: mujeres dominicanas en las peluquerías internacionales de Estación Central», desarrollada por Antonia Lara, en el marco del programa de Doctorado en Ciencias Sociales de la Universidad de Chile, y la otra denominada «Fronteras, sexualidades y procesos de subjetivación. Migrantes 
de esta idea se realiza a partir de relatos de migración construidos mediante el trabajo de campo de ambos estudios. ${ }^{2}$

Partiendo de la noción de movimiento migratorio que Sayad (1991) elabora en las coordenadas del desplazamiento (espacio) y la provisoriedad (tiempo), planteamos que este movimiento se puede considerar como un trayecto de subjetivación, es decir, como trayecto de encuentro con la alteridad, con la dimensión de lo extraño tanto respecto a otros (en el campo de las problemáticas identitarias) como respecto a sí mismo. Es preciso considerar que, dadas las características de los tránsitos estudiados, se trata de experiencias de migración que no fueron explícitamente forzadas por situaciones de violencia política y social, como en el caso de la migración por búsqueda de asilo o refugio, y tampoco constituyen migraciones temporales (es decir, con un momento de retorno definido previamente, y a corto plazo). Por otra parte, como dato relevante para la lectura del análisis, si bien existe cierta heterogeneidad de clase en el grupo de entrevistados, en términos generales no son experiencias que correspondan a personas precarizadas.

Esta reflexión busca aportar al campo de los estudios migratorios, en el que la noción de extrañamiento se ha utilizado principalmente para describir las dinámicas de inclusión/exclusión y de identidad/pertenencia de los extranjeros respecto a la sociedad a la que llegan (Checa, 2003). En esa misma línea, se ha propuesto como una idea que describe el encuentro cultural ya no con el carácter de shock o choque, sino como una relación con la alteridad que resulta extraña y, en ese sentido, incomprensible. Se habla, entonces, de extrañamiento cultural como «un desconocimiento de los patrones culturales de la alteridad» (Checa et al., 2007: 122), propio de todo proceso de encuentro con la diversidad.

Desde el lado del migrante, se alude a la idea de extrañar como el sentimiento de falta de algo o alguien, o de extrañarse (y sentirse extrañado) en la trayectoria de «inserción», respecto a algún aspecto de la sociedad receptora (Stefoni y Bonhomme, 2014), pero, además, de la experiencia que impulsa una recreación del hogar en el país de destino (Bonhomme, 2013). También desde la perspectiva del sujeto, Ahmed (1999) exploró la idea de extrañamiento con relación a la migración entendiéndola como el proceso de extrañarse respecto a aquello que era habitado como hogar (Ahmed, 1999: 343, traducción propia), desde una concepción compleja de hogar que no puede ser equiparada directamente al país de origen, ni al hogar que se tiene o tuvo allí. Sin embargo,

LGTBIQ colombianos y peruanos en Santiago de Chile», llevada a cabo por Fernanda Stang, en el Doctorado en Estudios Sociales de América Latina, de la Universidad Nacional de Córdoba, Argentina. Además, este artículo se benefició del trabajo y las reflexiones generadas en el marco del proyecto de investigación «Trayectorias de personas migrantes no heterosexuales en Chile: desigualdades, violencias y resistencias» (Fondecyt regular 1210165), dirigido por Caterine Galaz, y en el que las autoras de este texto son co-investigadoras.

2. Si bien estos dos estudios no fueron diseñados y desarrollados con el objetivo de explorar este tipo de experiencias, la emergencia de este hallazgo común refuerza la entidad de este proceso social. 
la noción de extrañamiento que experimenta el migrante a partir de la imagen de otro racializado, etnificado, generizado, entre otras dimensiones, que le devuelve la sociedad receptora, y el impacto subjetivo de aquello, ha sido poco explorada.

A la luz de los relatos de migración recogidos en el trabajo de campo, nos interesa justamente reflexionar sobre este último sentido, y con relación a las siguientes interrogantes: ¿qué impactos subjetivos imprime en el migrante aquella experiencia de extrañamiento respecto a sí mismo que se le devuelve de manera parcial y discontinua?, ¿cómo se las arregla el sujeto con aquello? Se trata de la experiencia de extrañamiento en el encuentro con aquella imagen de alteridad de sí que recibe de la sociedad receptora en la vida cotidiana. Lo anterior se vincula a la «extrañeza social» respecto al migrante, la que, como señala Simmel, no es algo del individuo, sino que surge desde la relación con la sociedad que así lo califica: «En el caso del extranjero al país, ciudad, raza, etcétera todo lo que no se tiene en común no es, sin embargo, algo propio del individuo, sino que pertenece a la extrañeza de su origen» (2012: 25-26). Cuando aquello dista del concepto que tienen de sí, o de un aspecto de sí, en ocasiones, lleva al migrante a reflexionar sobre su lugar y a reposicionarse como sujeto de enunciación desde donde decirse (Hall, 1996).

Esta indagación tiene como telón de fondo la pregunta planteada por Brah (1996) respecto a cómo analizar la subjetividad poscolonial racializada y de género teorizando el vínculo entre la realidad social y la realidad psíquica (Freud, 1921; Elías, 1977), considerando que el sujeto colonial, tal como plantea Fanon, está «sobredeterminado desde el exterior» (2015: 115), desde las «miradas blancas, las únicas verdaderas» (2015: 115) que lo dejan fijado.

Este proceso se despliega en el campo de la alteridad, es decir, en la relación intrínseca con lo otro, en la medida en que lo identificado como tal permite la constitución de "nosotros», así como la constitución del tercer espacio de enunciación que propone Bhabha al analizar el discurso colonial. Este tercer espacio se constituye como el lugar entre [in-between] identificaciones fijas que «abre la posibilidad de una hibridez cultural» (2011: 20). Se trata de la «rearticulación o traducción, de elementos que no son ni el Uno (...) ni el Otro (...) sino algo distinto» (2011: 47). Este intersticio cuestiona y supera las oposiciones binarias yo/otro del discurso colonial: «No es el Yo colonialista o el Otro colonizado, sino la perturbadora distancia inter-media [in-between] la que constituye la figura de la otredad colonial» (2011: 66). Nos sitúa así en una perspectiva intersticial de la diferencia cultural, en el pasaje liminar entre uno y otro.

Lo anterior será planteado en trayectos migratorios sur-sur, más concretamente, en migraciones de personas de países latinoamericanos (dominicanas, peruanas y colombianas) hacia Chile, específicamente a su ciudad capital, Santiago. Planteamos que en estos casos se ponen en juego des/encuentros con el otro en la forma de dinámicas de identificación/reconocimiento, jerárquicamente organizadas en las intersecciones del género, la nación y lo etnoracial. Lo que interesa analizar, entonces, son las maniobras subjetivas (prácticas y 
discursos) que los migrantes emprenden para vérselas con las implicancias que tocan al sujeto en estos des/encuentros con la imagen alterizada que se les devuelve, en particular con aquello que no calza respecto a sí mismo.

Para lo anterior, asumimos una perspectiva crítica respecto a la noción de identidad, planteada por autores como Bhabha (2011), Hall (1996) y Laclau (1993), quienes la sitúan como una operación fundamentalmente ideológica. Laclau alude a la identidad como «aquellas formas discursivas a través de las cuales la sociedad trata de instituirse a sí misma sobre la base del cierre, de la fijación del sentido» (1993: 20). El carácter ideológico reside en el hecho de que se trata de un discurso del cierre, el que sería constitutivo de lo social. Por su parte, Hall (1996) conceptualiza la identidad como "punto de sutura»y, en la misma línea, Bhabha postula las identidades nacionales como "puntos de adhesión», es decir, «esas maniobras ideológicas mediante las cuales se dota a las comunidades imaginadas de identidades esencialistas» (2010: 396).

Lo que interesa poner de relieve aquí es que, cuando nos referimos a identidades, estamos aludiendo a la coagulación, fijación y sutura del sentido en el proceso de identificación. Se trata de un discurso ideológico que, por sus efectos de totalización y esencialización, produce por ejemplo la relación naturalizada entre nacionalidad y cultura, o entre sexo y género. Postulamos que son aspectos de esta naturalización los que se ponen en tensión en el trayecto migratorio, tanto para los/as migrantes como para la sociedad de llegada. Lo anterior se vincula a que el migrante está expuesto cotidianamente a ser interpelado (Althusser, 1970) por «los discursos y prácticas que intentan (...) ponernos en nuestro lugar como sujetos sociales de discursos» (Hall, 1996: 28). Sin embargo, cuando el migrante no se reconoce del todo en aquellos lugares sociales en que se le ubica, se experimenta una sensación de extrañamiento. Esta sensación opera por medio de una desidentificación (Rancière, 1995) parcial y temporal, que hace tambalear algunas de sus certezas identitarias. Frente a ello, el sujeto busca reposicionarse, se toma como objeto para reflexionar sobre su lugar de enunciación, en esta situación de dislocación identitaria. Este movimiento reflexivo sobre sí puede concebirse como "pliegues del afuera o de subjetivación» (Deleuze, 1986), por medio de los que se busca incorporar aquello que vino de afuera y en lo que el sujeto ha quedado de algún modo implicado. Ahora bien, la experiencia de extrañamiento no impacta del mismo modo en la subjetividad de los migrantes $\mathrm{y}$, en tal medida, no para todos quienes migran la experiencia da pie a un reposicionamiento subjetivo, es decir, de resignificación de lo propio/lo ajeno y de su posición de enunciación (Hall, 1996).

En términos metodológicos, los estudios de los que emana esta reflexión fueron de carácter cualitativo. El primero de ellos buscó reconstruir los procesos de subjetivación de cinco mujeres dominicanas en Santiago de Chile desde una perspectiva biográfica (Bertaux, 1997), con quienes se realizaron entrevistas (en 4 a 5 encuentros con cada una) para la producción de relatos de migración (Arfuch, 2002). Este trabajo de campo se realizó entre septiembre de 2014 y septiembre de 2016. El segundo estudio se propuso explorar, a través de las tramas narrativas de migrantes de origen peruano y colombiano con 
Cuadro 1. Perfil de las/os entrevistadas/os

\begin{tabular}{|c|c|c|c|c|c|c|}
\hline $\begin{array}{l}\text { Nombre } \\
\text { ficticio }\end{array}$ & Edad & País de origen & $\begin{array}{l}\text { Tiempo de } \\
\text { residencia }\end{array}$ & Educación formal & Actividad & Migración previa \\
\hline Pilar & 35 & Rep. Dominicana & 2 años & Media completa & Camarera & Intentos fallidos \\
\hline María & 38 & Rep. Dominicana & 2 años & Curso peluquería & Peluquera & no \\
\hline Melisa & 30 & Rep. Dominicana & 4 años & Universitaria & Profesional & no \\
\hline Altagracia & 45 & Rep. Dominicana & 16 años & Posgrado & Comerciante & no \\
\hline Raquel & 52 & Rep. Dominicana & 18 años & Curso peluquería & Peluquera & no \\
\hline Ariel & 27 & Perú & 8 años & Media completa & Buscando trabajo & Interna-cional \\
\hline Daniela & 29 & Colombia & 2 años & Universitaria completa & Empleada de comercio & No \\
\hline Felipe & 19 & Colombia & 4 años & Universitaria en curso & Estudiante & No \\
\hline Laura & 38 & Colombia & 6 años & Posgrado en curso & Trabajadora informal & Interna \\
\hline Marcelo & 36 & Perú & 3 años & Universitaria incompleta & Empleado en peluquería & Interna \\
\hline Rodrigo & 36 & Perú & 14 años & Universitaria completa & Diseñador de prendas & Interna en Chile \\
\hline Vanesa & 38 & Colombia & 1 año & Posgrado completo & Buscando trabajo & Interna e interna-cional \\
\hline
\end{tabular}

Fuente: elaboración propia.

subjetivaciones sexogenéricas no normativas (en términos más institucionalizados, personas LBTBIQ+) que residían en Santiago de Chile, sus experiencias en torno a eventuales transformaciones - $\mathrm{O}$ persistencias - en sus procesos de subjetivación sexogenéricos a partir de la llegada a una nueva configuración cultural nacional, a causa de su migración. Esta investigación adoptó un enfoque biográfico (Arfuch, 2002) y recurrió principalmente al relato de vida como técnica de recogida de información (Bertaux, 1997; Velasco y Gianturco, 2012). El trabajo de campo de este estudio se realizó entre abril de 2014 y abril de 2016. La muestra estuvo compuesta por siete personas migrantes de entre 19 y 38 años, y con tiempos de residencia variables en la ciudad (de 1 a 14 años). Con cada caso se mantuvieron tres largos encuentros de conversación, y en algunos casos cuatro, más otros encuentros informales, cuya textualización fue analizada mediante el programa NVivo, en un uso sui géneris del software. ${ }^{3}$ En el cuadro 1 se especifican algunas características relevantes de las personas entrevistadas:

En la primera parte de este artículo se explora la experiencia de extrañamiento en relación con la idea de frontera, para exponer algunos aportes conceptuales a la construcción de esta noción. En la segunda se realiza un ejercicio semejante pero acercándose a la experiencia de extrañamiento desde dos ámbitos disciplinarios: la etnografía y el psicoanálisis. En la tercera parte se analizan escenas de extrañamiento recogidas en el trabajo de campo de ambos estudios y se exponen fragmentos de los relatos migratorios que ponen en juego la experiencia de extrañamiento en el cruce de fronteras, respecto a las maneras

3. Dado que el corpus generado en este segundo estudio se abordó a partir del análisis crítico del discurso, el programa NVivo se utilizó solamente para la codificación del texto mediante categorías emergentes, agrupadas luego en las dimensiones definidas para el análisis. 
de decir y a los pliegues en la identificación como extranjeros/as. Por último, se proponen conclusiones surgidas de este recorrido en torno a aproximaciones conceptuales y experienciales al extrañamiento.

\section{Fronteras y extrañamiento}

\subsection{Sayad: en el cruce de fronteras "se nace como migrante"}

En el campo de los estudios migratorios, Sayad (1991) señala que emigración e inmigración son dos caras de un mismo proceso y que, por tanto, es necesario considerar esta condición doble de emigrante e inmigrante a la vez. Este autor plantea la lógica del movimiento migratorio como un desplazamiento de personas (en el espacio) que es considerado, tanto por los propios migrantes como por los estados, como provisorio (en el tiempo). Para el autor, en este movimiento no se trata solo del desplazamiento en el espacio físico, sino también en espacios sociales, económicos, políticos, culturales, así como subjetivos.

El desplazamiento migratorio suele asociarse a la noción de dislocación. Este término sitúa la experiencia migratoria en el campo semántico de aquello que implica salirse de «su lugar» cultural, social y subjetivo. Así como un hueso se disloca, es decir, se sale anómalamente del lugar donde cumple su función en el cuerpo, en la misma forma, la migración de personas es asumida por los estados como una situación excepcional y, por tanto, temporal y provisoria. Lo anterior se sostiene en un implícito normativo que se asume con la fuerza de lo natural: que al lugar de nacimiento siempre se debe volver, aun cuando sea a morir. Entonces, el retorno, como vuelta al origen, opera como un imperativo del que la noción de dislocación es tributaria, en la medida en que supone que hay un lugar, una nación, del que cada uno de nosotros «es» y al que, por tanto, pertenece «naturalmente». Es decir, un lugar, y solo uno, al que se pertenece completamente, y es a este lugar al que se debe retornar — Ahmed (1999), sin embargo, cuestiona esta idea sosteniendo que el hogar, como lugar al que se retorna, es una construcción de los afectos, y no necesariamente coincide con el país de origen. En este aspecto, Shütz (2012) plantea que en el retorno no se encuentra el hogar que se dejó (que se recordaba o añoraba): «Y, por la misma razón, el que vuelve al hogar no es el mismo hombre que lo abandonó. No es el mismo ni para él ni para aquellos que esperan su retorno» (2012: 53). Este último aspecto, no ser el mismo para el propio sujeto, es lo que nos interesa explorar.

De tal modo, la idea del retorno como horizonte del trayecto migratorio dota a este de un carácter provisional. Como señala Sayad (1999), aun cuando en los hechos se aplace sucesivamente el momento del retorno, este nunca llega a diluirse del todo, sino que se sostiene como una instancia por llegar que suele situarse en algún hito biográfico como el matrimonio, la crianza de los hijos/ as, el trabajo, la enfermedad, la muerte, etcétera.

Aunque podría argumentarse que los migrantes no viajan completamente «ciegos» sobre el lugar al que llegarán, pues la migración comienza a fraguarse 
desde que se toma la decisión y se prepara el viaje, se considera que siempre hay un espacio entre «la imagen que se tiene del paradero y las condiciones reales de vida que los inmigrantes experimentan allí donde llegan» (Izquierdo Escribano, 2000: 227). Es decir, el cruce de fronteras conforma, de alguna manera y en cierta medida, una experiencia de descalce. Asimismo, muchas de las migraciones transnacionales tienen un itinerario previo de migración «interna» $y$, de algún modo, las personas se han ido configurando como migrantes antes del cruce de fronteras internacionales. Sin embargo, siguiendo a Sayad (1991), diremos que en el cruce de fronteras se da un cambio de estatuto, un paso de la emigración a la inmigración, cuando se es nominado por primera vez como inmigrante. En esta medida, Sayad enfatiza que resulta un acto inaugural para el sujeto, ya que «el migrante nace ese día para la sociedad que así lo designa» (1991: 16). A decir del autor, este acto se acompaña de «una reacción de extrañeza en el sentido fuerte del término: la relativización que el emigrado (...) ha experimentado (...), equivale al descubrimiento no solo de lo arbitrario cultural, (...), sino también de la historia» (Sayad, 1999: 138). Esta reacción de extrañeza abre para el sujeto una perspectiva de exterioridad, del afuera social y cultural en el que ahora se encuentra, del lugar de alteridad en que es situado, en las coordenadas, valoraciones y códigos socioculturales del lugar de llegada. Esto abre una distancia en el sujeto respecto a lo que identitariamente considera «lo propio» (lo que trae desde el lugar de partida), la que implica que el sujeto se tome como objeto, en la medida en que es «sujeto de cogitación ante sí mismo y los otros» (Bleichmar, 2010: 11).

Este proceso se expresa más evidentemente en la configuración identitaria, es decir, en sus certezas respecto a quién es y de dónde es, algunas de las cuales se verán cuestionadas y otras reafirmadas. Así, el sujeto migrante, lejos de quedar pasivo respecto a la dislocación identitaria, toma posición, se relocaliza en el nuevo escenario, como sujeto de enunciación respecto a sí mismo. Estas posiciones son los movimientos y maniobras subjetivas que le permiten lidiar con la posición de descalce de la norma de la identidad y pertenencia única (etnonacional, de género, clase, «raza»).

Lo que nos interesa, entonces, es ahondar en este acto inaugural que Sayad (1991) sitúa en el cruce de fronteras, y que muchas veces se acompaña de una reacción de extrañamiento, en palabras del autor, pero que no continúa desarrollando a lo largo de su obra. Nos parece que allí se imprime una modalidad del impacto que la experiencia migratoria tiene en el sujeto, y que ha sido poco examinada.

\subsection{La frontera como traducción (cultural)}

Otro aspecto de la relación entre migración, frontera y extrañamiento que nos interesa explorar se refiere al extrañamiento subjetivo que se experimenta por el cruce de una frontera entre configuraciones culturales nacionales, y que compromete varias dimensiones del proceso de subjetivación. Para abordarlo, 
es preciso explicitar la idea de configuración cultural nacional que está en la base de esta propuesta.

Al hablar de «migración internacional» se da por supuesta la presencia de una frontera entre estados nacionales, lo que implica a la vez una multiplicidad de fronteras: la jurídico-política, la institucional (aduanas, fuerzas de seguridad y control de migraciones), la económica (entre sistemas productivos), la soberana (que establece territorios de actuación de las fuerzas represivas y derechos de ciudadanía diferenciales), la identitaria, y la que se establece entre regímenes de significados (Grimson, 2012). Es en relación a estos dos últimos puntos que aparece la idea de configuración cultural nacional.

La distinción de este concepto es relevante porque los límites de un estado no necesariamente coinciden con los límites de una configuración cultural nacional. Más aún, pensar fronteras entre configuraciones culturales nacionales tampoco implica pensar que los campos delimitados por ellas son homogéneos a su interior, ni que esas fronteras son claras, absolutas e inmutables. Dentro de una configuración cultural nacional pueden convivir, luchar, intersecarse y superponerse otras, que a su vez pueden desbordar esos límites geopolíticos.

Sin embargo, tampoco hay que desconocer el notable poder del estado en la producción de formaciones nacionales de alteridad ${ }^{4}$ (Segato, 2007) y, por lo tanto, en el proceso de fronterización cultural e identitario. Las investigaciones empíricas han mostrado que las fronteras nacionales, más allá de su historicidad y contingencia, son importantes barreras identitarias (Grimson, 2000), y que en América Latina, por ejemplo, siguen siendo artefactos muy potentes, aun a pesar de que casi ninguna frontera coincide con una diferencia cultural previa (Caggiano, 2003).

A la luz de estas consideraciones, podemos afirmar que el migrante internacional, al atravesar la frontera del estado hacia el que se desplaza, ha arribado también a una nueva configuración cultural nacional, que abre un nuevo campo de posibilidad de representaciones, prácticas y relaciones institucionales. Esto supone una lógica distinta de articulación entre sus partes (una forma específica de articulación de la heterogeneidad), otra trama simbólica, y por lo tanto ofrece nuevos elementos para articular en la construcción de las diversas dimensiones implicadas en nuestros procesos de subjetivación ${ }^{5}$ — nacional,

4. La idea de formaciones nacionales de alteridad alude al hecho de que «los procesos de otrificación, racialización y etnitización (sic) propios de la construcción de los estados nacionales emanan de una historia que transcurre dentro de los confines, y al mismo tiempo plasma el paisaje geográfico y humano de cada país» (Segato, 2007: 28).

5. La noción de configuración cultural acuñada por Grimson (2012) propone que hay cuatro elementos que la caracterizan: las configuraciones son campos de posibilidad —en cualquier espacio social hay representaciones, prácticas e instituciones posibles, imposibles y hegemónicas_-; suponen una lógica de interrelación entre las partes que le es particular; implican una trama simbólica común, lenguajes verbales, sonoros y visuales en los cuales quienes disputan pueden a la vez entenderse y enfrentarse, y además tienen «algo» compartido. En definitiva, «la noción de configuración cultural busca vincular las tramas de prácticas y significados con fronteras de significación dentro de las cuales hay desigualdades, poderes e historia» (Grimson, 2012: 139). 
étnica, de clase, genérico-sexual, entre otras-, que pueden traducirse en nuevas formas de constricción, pero también en potencialidades liberadoras.

Tomamos prestada de Diana Maffía la figura de la frontera como espacio de traducción, una idea con la que la autora alude al "proceso que establece una zona de negociación generadora de sentidos entre culturas, negociación sin la cual el diálogo y la comunicación es imposible» (Maffía, 2007: s/n). Entendemos que el de traducción es un esfuerzo de doble faz, puesto que para negociar es preciso ver/sentir las diferencias entre las configuraciones culturales que se traducen, y experimentar sus contradicciones. En definitiva, hacerse consciente de sus arbitrariedades, o vivenciarlas de modos más difusos, o menos reflexivos. El extrañamiento alude precisamente a la tensión experimentada respecto a ese arbitrario cultural encarnado.

Al cruzar la frontera, el migrante es traducido en varias imágenes de sí que no había experimentado. Esta multiplicación es una suerte de movimiento inverso al que describió Lacan con su noción del estadio del espejo, ese momento-proceso en el que el bebé se encuentra con una imagen de sí — del yo $[j e]$ - que le da unidad a la experimentación hasta entonces fragmentada de su cuerpo (Lacan, 1966; Blasco, 1993). En cambio, «[e]l espejo-frontera fragmenta la unidad ilusoria, imaginada, del sujeto, y convierte al migrante en un sujeto-cuerpo en el que coexisten, muchas veces de manera contradictoria, tramas socioculturales diferentes» (Stang, 2019: 27), con sus propias jerarquías sociales (de clase, étnico-raciales, de género, etcétera). Los sujetos migran llevando consigo tropos y lógicas de sus lugares de origen (Gutiérrez Rodríguez, 2005: 85), que en el proceso de extrañamiento que implica el cruce de la frontera entre configuraciones culturales nacionales pueden emerger como tematizaciones, ${ }^{6}$ en la medida en que revelan diferencias respecto a los tropos y lógicas del lugar al que se llega.

Esta mirada del extrañamiento está estrechamente asociada a una concepción intersticial de la frontera (Stang, 2020), que supone derivas diferentes de las que pueden surgir de la frontera pensada como límite. Esa posición intersticial se relaciona con el lugar ambiguo del entre, de la no pertenencia plena a un "en» o al otro, que supone el convertirse en extranjero, sobre todo en los primeros años de esta experiencia. Es en ese punto que la experiencia de extrañamiento se traduce en transformaciones en el proceso de subjetivación. Es esa vivencia de la ambigüedad que genera el estar siendo algo que se está dejando de ser, y a la vez el empezar a ser algo que aún no se es completamente (Eribon, 1999), que impacta de manera significativa la construcción de subjetividad. Es decir, «[e]sa experimentación del estar entre, esa posición intersticial, esa no pertenencia plena ni a la configuración cultural de la que se partió ni a aquella a la que se llegó» (Stang, 2020: 27) permiten renegociar las fronteras a partir de las que se construyen las subjetividades, entendiendo la subjetividad como efecto de negociación de las fronteras (Sabsay, 2011), mediante luchas coti-

6. Entendiendo por tematizar la aprehensión de un determinado referente que se realiza mediante la enunciación, y la forma que se le da (Stang, 2018). 
dianas que desafían los dispositivos de sujeción que ponen fronteras a nuestras vidas, desafío que se realiza a través de prácticas de subjetivación.

Los énfasis en la concepción intersticial y procesual de la frontera buscan, como decimos, desvincular la idea de frontera de su relación unívoca con un límite geopolítico (aunque este sea una parte de ella), a la vez que desligarla de la imagen de un cruce que ocurre en un momento y de una sola vez. Como lo mostraron las personas migrantes con las que se trabajó, ese cruce de frontera podía iniciarse mucho antes de la llegada a Chile, en el momento de decidir la migración, y se seguía reconstruyendo desde las experiencias en el país de destino.

\section{Algunas aproximaciones al extrañamiento: etnografía y psicoanálisis}

En este apartado nos proponemos revisar dos ámbitos en los que la noción de extrañamiento es utilizada y que son colindantes con aquel que proponemos para analizar los relatos de experiencia migratoria. Lo anterior nos permite delinear aquello que entendemos por experiencia de extrañamiento, para construir una definición provisional de la concepción emergente a la que pretendemos llegar: la de extrañamiento subjetivo en el proceso migratorio. Primero, plantearemos el lugar que tiene esta noción en la construcción de conocimiento etnográfico, mediante el ejercicio de descotidianizar (Lins, 2004) y de descentramiento (Velasco y Díaz de la Rada, 1997). A la vez, interesa situar el tratamiento que desde el psicoanálisis se le ha dado al término de extrañamiento, a través de la experiencia de lo ominoso (Freud, 1919), en el que se posiciona lo extraño o ajeno ya no en otro, sino en la constitución misma del sujeto.

\subsection{El trabajo etnográfico desde la posición de extrañamiento}

Una primera arista que nos interesa indagar es la forma en que la posición de extrañamiento ha sido asumida por el trabajo etnográfico como un modo de producir conocimiento. En la antropología sociocultural, el método etnográfico de investigación busca dar inteligibilidad a aquello que a primera vista resulta distinto y distante (Velasco y Díaz de Rada, 1997). Con este propósito, la noción de extrañamiento se ha planteado como una condición fundamental (Lins, 2004), así como una capacidad o actitud (Velasco y Díaz de Rada, 1997; Olmos, 2016) que consiste en sorprenderse e interesarse por conocer el mundo sociocultural de otros. A decir de Olmos, la actitud de extrañamiento se despierta cuando formas de entender la realidad y de ponerlas en práctica «no encajan en nuestra visión corriente de las cosas» (2016: 150), y se busca dar lugar a aquello para hacerlo inteligible. Así, extrañamiento y descalce con lo esperado, con lo habitual, aparecen como nociones próximas desde las aproximaciones etnográficas.

Ahora bien, Olmos (2016) señala que cuando se realiza trabajo de campo en contextos que conocemos bien, la posición de extrañamiento se asume como un ejercicio consciente en el que se busca «convertir lo familiar en exó- 
tico» (Lins, 2004: 195). El autor sitúa el «descotidianizar» en la noción de conciencia práctica del mundo de la vida cotidiana, es decir, de aquellas reglas tácitas que parecen naturales y obvias, a las que respondemos espontáneamente con un conocimiento que permite desenvolverse fluidamente y que resultan aproblemáticas (Schütz, 2001; 2012). A través del extrañamiento de lo obvio, el trabajo del etnógrafo en el campo funciona como un «rompedor de rutinas de la vida social y del carácter natural» (Lins, 2004: 56). Se puede pensar el símil con la figura del extranjero, pues aquello que el etnógrafo procura hacer de modo consciente, lo experimenta de manera espontánea el sujeto en su primer tiempo de migración en un lugar al que llega por primera vez. Es decir, la mayor parte de lo que se vive en el día a día tiene el carácter de lo extraordinario, en el sentido de lo que no le es cotidiano (aún) y lo observa desde una posición exterior. Así, en las preguntas del migrante sobre, por ejemplo, el significado de una sigla al hacer un trámite, sobre cómo funciona el transporte público o al equivocarse en el saludo (un beso, dos, sin beso, etcétera), lo cotidiano, o sea, lo dado, resulta problematizado en función de un conocimiento práctico que no comparte. Cierto es también que muchos migrantes, producto de las redes con las que cuentan al llegar o como reacción a lo anterior, se insertan en grupos de connacionales o de otros migrantes donde las prácticas son ya conocidas o familiares. Sin embargo sostenemos que, en distinta medida o intensidad, estas experiencias de lo extraordinario están presentes en el primer tiempo de la migración internacional.

A través del extrañamiento, el etnógrafo (y el migrante internacional que llega por primera vez a un lugar que le resulta ajeno) genera una forma de conocimiento que opera por medio de la "comparación implícita» (Velasco y Díaz de Rada, 1997: 149). Es decir, en el encuentro con las maneras de hacer y de decir del otro (Certeau, 1996) hay una constante producción de diferencias, tanto culturales como sociales y económicas. En el caso de los migrantes internacionales con los que trabajamos, si bien se insertan muchas veces en ámbitos híbridos, es decir, que no son puramente de la sociedad receptora, sino ya mezclados con las prácticas socioculturales de los propios migrantes latinoamericanos, también se producen estas comparaciones, en términos de diferencias y semejanzas con las prácticas y costumbres de otros.

Ahora bien, al mismo tiempo que el ejercicio de «descotidianizar» (y el extrañamiento) pone de relieve la distancia al hacer un quiebre con lo cotidiano, en la investigación etnográfica el trabajo de campo también implica un descentramiento de sí, es decir, una distancia respecto «de su propia realidad y vida cotidiana y de sus categorías ordinarias de interpretación de la realidad" (Velasco y Díaz de Rada, 1997: 143) que permite aprehender al otro. Este descentramiento puede relacionarse con lo que Sayad (1991) nombra como la dimensión epistemológica que se abre en el cruce de fronteras y que permite al migrante mirarse desde fuera. Ahora bien, es relevante señalar que el símil que planteamos entre la posición del migrante y la del etnógrafo no es del todo equivalente, ya que el etnógrafo la busca de manera deliberada en su propósito de conocer, mientras que al migrante se le impone en el día a día e intenta conocer como necesidad 
de vida práctica. Con todo, como señala Simmel (2012), el extranjero como figura de alteridad "significa la cercanía de lo lejano" (21) y, en tal medida, se trata de una posición en «una mezcla sui generis de lejanía y proximidad» (23) respecto al otro que le "confiere objetividad al extranjero» (24).

De tal modo, siguiendo el señalamiento de Lins (2004), diremos que el extrañamiento se conforma como una "unidad contradictoria», en la medida en que es «al mismo tiempo aproximación y distanciamiento» (2004: 65), respecto a los otros y a sí mismo. Esta posición paradójica permite conocer el mundo del otro, ya sea de modo consciente y sistemático, como el etnógrafo, o de manera espontánea en la vida cotidiana, como el migrante. En este último caso, se abren posibilidades a un conocimiento de sí no advertido previamente.

\section{Experiencia de lo ominoso: la inquietante extrañeza de lo extranjero en nosotros mismos}

Respecto a la indagación por el afecto que acompaña la experiencia de extrañamiento, es decir, lo que Sayad (1999) nombra como reacción de extrañamiento, el texto de Freud (1919) Lo ominoso (Das Unheimliche), también traducido como «inquietante extrañeza», aporta algunas claves de lectura. En la literatura psicoanalítica, lo extranjero está vinculado a la hipótesis del inconsciente, por tanto, se la señala no como una figura exterior al sujeto, la del semejante o del enemigo (Viñar, 1998), como se le concibe en el sentido común, sino en relación con el sujeto mismo - la extranjería interior (Bornhauser, 2012). Hablamos aquí de lo reprimido freudiano y su retorno, como experiencia de extrañamiento del yo respecto a sus propias producciones en la vida cotidiana (sueño, lapsus, chiste) (Freud, 1901); y de lo que Kristeva elabora como "[e]xtraños para nosotros mismos», en relación con lo reprimido que constituye al sujeto: «El otro de la muerte, el otro de la mujer y el otro de la pulsión indomeñable. Lo extranjero está en nosotros» (1988: 366).

En el texto freudiano de 1919, siguiendo la línea del «Sentido antitético de las palabras antiguas" (1910), el autor se aboca a "pesquisar el significado que el desarrollo de la lengua sedimentó en la palabra ominoso» (1919: 220). Se establece entonces que heimliche es lo contrario de un-heimliche (ya que un- es prefijo de negación, aclara Freud en el pie de página 220). De manera tal que heimliche tiene como significado aquello perteneciente a la casa, la familia, lo íntimo, lo que recuerda al terruño, la protección y lo seguro, mientras que su negación, un-heimliche, se entiende como lo terrorífico, desasosegante, horroroso, angustioso. Sin embargo, señala Freud (1919), de esta indagación lo relevante es que heimliche tiene un significado que coincide con su opuesto, a saber: «Mantener algo clandestino, ocultarlo para que otros no sepan de ello ni acerca de ello, escondérselo (...). Hacer algo (...) a espaldas de alguien» (1919: 223). Es decir, donde «heimlich deviene unheimlich» (1919: 226), teniendo como significado lo familiar y oculto a la vez.

Sin embargo, la elaboración que le permite a Freud dilucidar el mecanismo de la experiencia de lo ominoso es la de Schelling. Este último señala que la 
inquietante extrañeza (unheimlich) es una variedad particular de lo terrorífico, un afecto que se experimenta cuando «lo que está destinado a permanecer en secreto, en lo oculto, ha salido a la luz» (Freud, 1919: 224). Para Freud, se trata de un afecto angustioso que emerge ante lo que Kristeva elabora como «nuestra perturbadora alteridad» (1988: 367), ya no como una manifestación patológica, sino como dinámica psíquica (represión). Para esta última autora, se trata de una identificación con el otro por medio del asombro ante lo insólito, que puede dar pie a una «apertura hacia lo nuevo, en una tentativa de adaptación a lo incongruente» (1991: 364). Esta idea permite entender el modo en que el estar ubicado en un lugar de alteridad, en ocasiones, devela algún aspecto desconocido de sí, oculto hasta ese momento. En la medida en la que toca a su posición subjetiva, se trata de una suerte de proceso de autoconocimiento no esperado.

\section{Relatos: escenas de extrañamiento}

\subsection{Pliegue en la identificación como extranjera y doblez de la pertenencia}

Como hemos dicho siguiendo a Sayad (1999), en el desplazamiento migratorio se abre para el sujeto la dimensión arbitraria de la cultura. Una de las implicancias de ello es que el sujeto toma distancia de su cultura y se sitúa temporalmente desde una posición de exterioridad. Esto trae aparejado, entre otras cosas, que se produzca una distancia respecto a sí mismo, por ejemplo, la resignificación de lo que se consideraba como lo propio (costumbres, valores, prácticas, etcétera). Sin embargo, la experiencia de extrañamiento puede tener la deriva de un repliegue identitario a lo propio, en el que predominan las prácticas culturales de origen que, entendidas en clave nacional, tienen su expresión en la incorporación a colectivos de connacionales en los que estas se reproducen. Así, no solo se dan procesos de elaboración e incorporaciones parciales de aquello respecto a lo cual se queda implicado en la experiencia de extrañamiento, sino también de resistencia, negación o fijación a lo que se consideran las propias prácticas culturales.

Esta distancia consiste no solo en la extranjerización de lo propio (Kristeva, 1988), sino que, en virtud de ella, el sujeto puede tomarse como objeto y reflexionar sobre su condición extranjera. Un ámbito en que esta experiencia se registra es en la manera de hablar, específicamente respecto a lo que se considera como la "propia» manera de hablar, así como las alteraciones (Viveiro de Castro, 2002) que de ella se tiene noticia, a través de otros, en el trayecto migratorio.

Es así que, cuando las migrantes latinoamericanas proyectan un destino como Chile, es decir, que se desplazan entre países de habla hispana, asumen como una ventaja el hecho de continuar hablando en su idioma. Sin embargo, a poco andar, la experiencia las confronta con el hecho de que, a pesar de compartir un mismo idioma, hay algunas diferencias en las maneras de decir que hacen que no entiendan y no sean entendidas del todo al hablar. 
De tal modo, hay una necesidad práctica de estar traduciendo cotidianamente palabras y modismos, así como entonaciones, acentuaciones y modulaciones, que expresan connotaciones y dobles sentidos al hablar.

En efecto, Raquel (mujer dominicana, peluquera y dueña de peluquería, 16 años en Chile) relataba que al llegar a Chile le resultaba difícil entender lo que la gente le hablaba: «Yo pensaba que iba a ser más fácil que si fuera a un país como Estados Unidos, donde hablan inglés, pero al principio no les entendía las palabras que me decían y tampoco ellos me entendían a mí. Fue muy terrible. ¡Ay, Dios mío!» (Raquel, «Diario de campo», abril de 2016).

Así mismo, en el relato de Pilar (mujer dominicana, camarera, 2 años en Chile), se destacó la dificultad que tuvo, y que aún tenía, para entender lo que le pedían los clientes en su trabajo: «Al comienzo lo que más se me hizo extraño fueron las palabras que son diferentes. A veces no les entendía porque hablan muy rápido. Todavía hay algunos a los que les pregunto dos y tres veces, y algunas cosas no las decía porque no sabía si iban a estar bien o mal» (Pilar, "Diario de campo", mayo de 2016).

En ambos casos, se trata de la extrañeza en el sentido de no entender del todo las palabras y maneras de decir del otro, lo que trae aparejada una vacilación en el uso de las palabras, inseguridad al darse a entender y al entender lo que se le dice.

Ahora bien, para lidiar con aquella inseguridad al hablar, Raquel, para ganar la confianza de potenciales clientas que se quisieran peinar o cortar el pelo con ella, hacía un uso situacional (Piscitelli, 2008) y estratégico de modismos y entonaciones consideradas como "chilenas»: «Tuve que aprender a hablar en puro chileno. Entonces, ahí me entendían bien. Después, entre mujeres dominicanas, volvía y hablaba bien dominicana, pero con las clientas trataba de no hacerlo» (Raquel, «Diario de campo», mayo de 2016).

En el mismo sentido, Altagracia (mujer dominicana, comerciante, 19 años en Chile) también explicitaba el uso estratégico de ciertos modismos para darse a entender en el contexto chileno: «Yo uso altiro y luca, nada más. Yo creo que es ordinario, pero uno se acostumbra a decir lucas. Pero no digo poh, me entendí, cachai. A veces digo cachai cuando estoy con chileno, para que me entiendan, pero si se lo digo a dominicano se burlan» (Altagracia, "Diario de campo", septiembre de 2016). Esto da cuenta de una cierta incomodidad que ella experimenta al usarlos frente a connacionales y muestra las diferentes posiciones que asumen los y las migrantes respecto a los modismos del otro, ya que algunos/as los incorporan (total o parcialmente) y otros/as se resisten a hacerlo para mantener sus prácticas y valoraciones culturales. Ahora bien, interesa subrayar que este uso situacional y estratégico de ciertas palabras y modismos supone un «involucramiento no identitario» (Urbalejo, 2019), es decir, que los usen no implica que estén identificadas con el habla nacional chilena. En ese sentido, los modismos y palabras que se incorporan no terminan de fijarse de modo definitivo, sino que se pliegan y despliegan según las situaciones.

En un sentido similar, Melisa (mujer dominicana, profesional, 5 años en Chile) distinguía entre aquellos modismos que usaba y aquellos que se resistía 
a incorporar: «A veces uso el ya, ocupo a veces me sale o huevón cuando me molesto, pero ya poh no lo uso o cachai tampoco" (Melisa, "Diario de campo", noviembre de 2015). En su caso, ella no cedía, no utilizaba aquellos modismos con los que se sentía incómoda.

Respecto a esta incomodidad al usar modismos considerados "chilenos", Raquel lo explicaba en función de la idea de un cierto orden «natural» en la relación entre nacionalidad y maneras de hablar. Su explicación ilustra la posición de resistencia a incorporarlos y de molestia al escuchar decirlos por connacionales dominicanos:

Es que mi forma de hablar no la he cambiado mucho. No uso los modismos, nunca he dicho ya poh, ni cachai, porque eso les queda bonito a los chilenos. Cuando veo a un extranjero que dice cachai, eso lo encuentro tan grotesco, porque los modismos quedan bonitos en tu tierra, porque tú sabes cómo. Nosotros el coño, ;coñaaazo! A nosotros nos sale bien. Pero si ustedes lo dicen, dicen coño no más, no se va a notar que están enojados.

Esta sensación de molestia da cuenta de una experiencia de extrañeza al decir ciertas palabras con las que no están identificadas y que, por tanto, se significan como ajenas. Y es la comunidad, volver a hablar como dominicanas entre dominicanas/os, la que alivia y protege de esta experiencia de extrañamiento al usar palabras del otro.

De tal modo, en la distancia respecto a la «propia» manera de hablar y la comparación con «otras», se pone en juego el ámbito de las diferencias en el binomio «lo propio/lo ajeno». En este ámbito, se hacen maniobras, tales como transacciones en el uso situacional de los modismos, resistencia a usar algunos de ellos o incorporaciones de otros. En estas maniobras, aún no se advierten procesos reflexivos que lleven a reposicionamiento subjetivo.

Ahora bien, a pesar de que ellas evalúan que viviendo en Chile no han cambiado mucho su manera de hablar, en los diálogos con sus familiares que están en la República Dominicana (ya sea en los viajes de visita al país o a través del teléfono) se les reprocha, en ocasiones con la forma de una interpelación, que su manera de hablar ha cambiado más de lo que ellas habían percibido de sí mismas. De tal modo, Melisa se daba cuenta de que su manera de hablar no había permanecido intacta, ya que su familia se lo remarcaba: «Me molestaban mucho en mi familia por alguna que otra palabra. Lo mismo cuando estoy allá y hablo con alguien de acá, me dicen que me salen palabras chilenas» (Melisa, "Diario de campo", noviembre de 2015).

Por los mismos motivos, Altagracia señalaba estar precavida de no usar modismos chilenos cuando iba o hablaba con su familia en la República Dominicana: "Allá me preguntan: "¿Por qué hablas así, si tú eres dominicana?". Nosotros estamos muy identificados con nuestro país y la forma de hablar: “¡Háblame bien, muchacha!”. Y el hablar bien significa que le hable dominicano» (Altagracia, "Diario de campo», septiembre de 2016). Así, el uso de las palabras es interpretado como atributo de nacionalidad de quien las enuncia 
y, en una concepción naturalizada de la relación entre lugar de nacimiento y manera de hablar, se considera una transgresión que se debe rectificar para hacerla calzar nuevamente con el canon nacional (Lara, 2019).

En su relato, Raquel expresa su inquietud cuando, en un viaje de visita a la República Dominicana, su hermana le decía: «iPero si tú no eres chilena, no hables así, muchacha!» (Raquel, «Diario de campo», mayo de 2016). Esto la extrañaba al descolocarla respecto a la idea que tenía de su manera de hablar y la llevó a preguntarse: «iPero ven acá!, ¿ ¿ómo es que esto cambia?» (Raquel, «Diario de campo», mayo de 2016). Es decir, a pesar de la resistencia de Raquel a incorporar ciertos modismos chilenos, hay una consecuencia no calculada en el uso situacional que hace de ellos y que excede su intención. Esto se le devuelve, sorpresivamente para ella, desde el lugar que consideraba como "propio" (teniendo a su hermana como portavoz) y para el que ahora su manera de hablar resultaba extranjera, en una suerte de extranjerización del lugar de lo propio. Lo anterior toma la forma de una interpelación a no hablar como chilena, a corregir esa imagen perturbadora, para la hermana, de una mujer dominicana hablando como chilena. Ante la experiencia de quedar descolocada y extrañada, Raquel elabora una explicación de sus cambios al hablar que le permite relocalizarse, por medio de la figura del chip: «Pero después ya yo sabía que me entendían, entonces me cambiaba el chip y hablaba en puro dominicano. Ahora estoy entre los dos, porque con ninguno, porque cuando fui a dominicana me dominicanicé» (Raquel, «Relato de migración», mayo de 2016). De modo que la imagen que le devuelve su hermana, y que la descoloca, la extraña respecto a sí y es subjetivada como un "cambio de chip». Es decir, en su explicación se ubica en ese espacio entremedio (Bhabha, 2011), ni uno ni otro. Lo anterior deviene de la experiencia de extrañamiento de Raquel, en la que se descoloca al constatar que hay momentos en que ella cambia estratégicamente el chip y, sin embargo, en estos «retornos parciales» se le devela que, sin darse cuenta, el chip la ha cambiado a ella.

De esta manera, se ha abierto una fisura en lo que consideraba como «propio" y queda implicada en una reposición subjetiva en torno al vértice de la extranjeridad, al afirmar que "uno nunca deja de ser extranjero» (Raquel, "Diario de campo», mayo de 2016), extranjera aquí y allá, en que ya no se está «igualmente habitado por aquello que parece familiar» (Ahmed, 1999: 343, traducción propia). Una constatación en la que, más que una reivindicación transgresora, se desliza una cierta resignación respecto a estar referida a más de un lugar, en el espacio del entremedio (Bhabha, 2011). Esta posición es escenificada en el relato que hace Raquel sobre un momento en el aeropuerto de los Estados Unidos, donde hacía escala hacia otra ciudad en la que visitaría a su hija y nieta. Sin embargo, pierde su pasaporte y no puede continuar el viaje. Raquel cuenta que fue llevada a la policía de migraciones porque debían devolverla a "su país»: "Ellos me preguntaron si yo era ciudadana chilena, yo dije que no porque yo era ciudadana dominicana todavía. Entonces yo les decía: "Pero mándenme para mi país, que es donde yo vivo, si yo vengo de allá" (Raquel, "Diario de campo», mayo de 2016). De manera que, a pesar 
de identificarse como dominicana, en ese momento ella verbalizaba que su país era Chile, como país de residencia. Podemos decir que, en esta escena en el aeropuerto, se puso en evidencia el colapso de la pertenencia/identidad de Raquel como totalmente dominicana, al hacer una separación al interior de lo que considera «mi país»: por una parte, como lugar de residencia y, por otra, como lugar de nacimiento. Así, Ahmed señala: «Los viajes de migración implican una división del hogar como lugar de origen y el hogar como mundo sensorial de la experiencia cotidiana» (1999: 341, traducción propia). Es decir, lo que antes de la migración estaba unido ahora se ha separado (Strejilevich y Filc, 2015). Este doblez en la pertenencia nacional se desdobla de un lado o del otro según donde se encuentre localizada al enunciarlo: «Si está fuera de Chile y de República Dominicana, en un tercer país, Chile se enuncia como "mi país"; mientras que estando en Chile, República Dominicana se identifica como tal» (Lara, 2019: 250). En esta escena, Raquel responde, como hemos venido insistiendo, en un reposicionamiento subjetivo en el espacio liminar e híbrido del entremedio, es decir, asumiendo una pertenencia parcial, doble y simultánea, desde la que se sitúa (enuncia) al ser interpelada.

\section{Extrañamientos situacionales, constricciones y liberaciones}

Al cruzar la frontera -insistimos en el carácter procesual de este cruce-, el sujeto migrante se multiplica, es traducido en otras imágenes de sí mismo, y es llevado a mirarse, sentirse, pensarse, hurgarse, evaluarse en aspectos que hasta el momento no le resultaban "problemáticos», porque antes de cruzar la frontera-espejo, como decíamos, no había podido ver esas imágenes de sí (Stang, 2019). Esta actitud epistemológica, como dice Sayad, implica una vivencia de extrañarse de sí mismo a partir de las imágenes que proyectan de él estos otros, al ser traducido en esta configuración cultural nacional a la que llega y al ser "ubicado» en una jerarquía social diferente. Los fragmentos de los relatos biográficos que analizamos a continuación muestran materializaciones de ese proceso en las dimensiones étnica, racial, nacional y de clase.

Marcelo (peruano, estilista, 36 años, 3 viviendo en Santiago) expresa en su relato biográfico una incomodidad que se define en un doble extrañamiento: primero, respecto a lo que supone ser peruano en la formación nacional de alteridad del país de destino; segundo, con relación a una posición en la formación nacional de alteridad del país de origen, que hasta el momento no lo había interpelado del modo en que lo hace en este nuevo escenario.

En Chile, la peruanidad se significa principalmente a partir de la imagen del enemigo que habilita la construcción épica de la nación —a través de la Guerra del Pacífico- ${ }^{7}$ y de un fenotipo indígena andino que rememora aquello que la operación de blanqueamiento racial modernizadora sobre la que se construye el estado nación chileno procuró invisibilizar. En Marcelo, esos

7. La Guerra del Pacífico (1879-1883) fue un acontecimiento bélico que enfrentó Chile con Perú y Bolivia, y derivó en la definición de la frontera norte del primero. 
signos corporales son bastante evidentes, y eso implica experimentar tanto un rechazo étnico-nacional como ser puesto en un lugar en la jerarquía de clase que le es ambiguamente ajeno:

...yo soy de ver algo y comienzo a limpiar y siempre me decía [un compañero de trabajo chileno, en el centro de estética] "para eso vienen los peruanos», así me decía. Y yo un día sí me calenté y le dije: «El día que ganes...» — porque yo ganaba más que él一, «el día que ganes más plata que yo hablamos». Le dije: «Y qué pena que yo sea limpio y tú cochino [sucio]. Y qué pena que yo sea trabajador y tu ocioso, ¿eso es un chileno?». (...) Siempre era su juego eso, mandármela por ahí, que peruanas nanas, ${ }^{8}$ que para eso vienen, que mi color, ¿¿cómo me decía él? Como que yo era muy oscuro para él, que era muy blanco, siempre jugaba con eso, ¿me entiendes? (Marcelo, tercer encuentro, julio de 2015)

Esta vinculación implícita entre el orden étnico-racial y el de clase obedece a lo que Margulis (1999) denomina «racialización de las relaciones de clase», esto es, la manifestación en las clasificaciones sociales presentes de «un proceso histórico de constitución de las diferenciaciones sociales que se organiza, desde su inicio, sobre bases raciales» (Margulis, 1999: 38), y que está muy presente en las sociedades latinoamericanas. En el relato de Marcelo, la ambigua ajenidad de clase —además de la étnica y racial— se produce porque, como se lee en la cita, el migrante peruano en Chile es asociado en general con las clases bajas, a las que Marcelo no se siente ligado en Perú, y porque sin embargo el proceso migratorio implica para él un empobrecimiento, en buena medida vinculado a los límites económicos que le impone su condición de extranjeridad. ${ }^{?}$

Es decir, en el extrañamiento que genera el cruce de la frontera, Marcelo se reconoce peruano, y reconoce también el trastrocamiento de su condición de clase (o la movilidad social descendente que ha experimentado por su condición de extranjeridad), a partir de la imagen de sí que se le devuelve en la interacción con estos otros de su nuevo aquí. Este reconocimiento-extrañeza no se produce sin tensiones, porque por momentos expresa en su relato un rechazo a esa pertenencia nacional y a ese lugar de clase que no le correspondía en la configuración sociocultural del país de origen. Por ejemplo, cuenta que, haciendo un trámite en el Departamento de Extranjería y Migración, escondió su pasaporte por un episodio con una mujer peruana que lo avergonzó:

...escondí mi pasaporte, porque había una señora sentada al frente, una señora con sus dos, tres hijos, y era como... y un señor: «Señora, vea a su cabrito [niño en Chile]». El cabrito en Perú significa mariconcito, gay, loca. «No, que mi hijo no es cabrito, cabrito son los maricones». Y yo así, «oh», escondí mi pasaporte...

8. En Chile se utiliza la expresión «nana» para referirse a las mujeres dedicadas al trabajo de casa particular o servicio doméstico.

9. Este extrañamiento de clase apareció en varios de los entrevistados del segundo estudio que estamos considerando, lo que lógicamente se relaciona con la característica de la muestra en este aspecto: la pertenencia mayoritaria a la difusa categoría de clase media. 
Todo el mundo, te lo juro, que volteó y la miró, asco, cólera, pena, no sé, la miraron feo. Entonces yo digo, está bien, no todos tenemos una educación, pero tienes un criterio, (...) hay que respetar, estás en un país donde no es el tuyo. Esas cosas a mí me molestan, porque he escuchado a peruanos, cuando he estado en eventos peruanos: "Ah, chileno culiado». ¿Cómo le dices chileno culiado a un chileno que te está abriendo las puertas de su casa? No puedes, es imposible, no puedes. Entonces esas cosas a mí me molestan, y lo escucho de mis propios compatriotas, que también lo cuentan, entonces esas cosas a mí me molestan. Ahí es donde siento yo como rechazo. (Marcelo, tercer encuentro, julio de 2015)

En esta escena, Marcelo expresa una incomodidad con este reconocerse peruano, pero también con el reconocimiento de una distancia de clase. De todos modos, esta incomodidad no alcanza a transformarse en una actitud de hurgarse como objeto. Aun así, ocurre esta reacción de extrañamiento, expresada en la tematización de la situación.

«Estás en un país donde no es el tuyo», ese enunciado que aparece en la cita también está estrechamente vinculado a un extrañamiento ligado directamente a la condición de extranjeridad, el extrañamiento implicado en la ajenidad del lazo con este estado nación al que se llega. En la medida en que el migrante se asume como que no es parte plena, adquiere imaginariamente una deuda por aquello que ese estado nación y esa sociedad nacional le permiten, aunque eso no suponga más que el estar. En esa operación hay una apropiación de la lógica estatal de parte del migrante, por la que asume que su presencia solo es legítima en su país de origen.

Entonces, con este múltiple extrañamiento que supone el cruce de la frontera, el migrante es traducido en una nueva parrilla de jerarquizaciones sociales, propia de la configuración cultural nacional a la que llega, pero a su vez migra encarnando las lógicas de la cartografía de diferenciación de su configuración social y cultural de origen. Esas lógicas de distinción que migran con él lo ponen también en tensión con los estereotipos que en el país de destino homogeneizan a quienes proceden del país de origen. Como se observa en los fragmentos de su relato, esa tensión atraviesa el discurso de Marcelo.

En el caso de Rodrigo (peruano, diseñador de vestuario, 36 años y 14 viviendo en Chile), dado que estos signos corpóreos de la "peruanidad» no son evidentes como en el caso de Marcelo, el extrañamiento étnico-nacional produce, en vez de una actitud de distanciamiento, una reacción reivindicativa:

...cuando les cuento que soy peruano o sienten un acento raro y me dicen: «¿Tú de dónde eres». «Soy de Perú». "Ah, no pareces peruano». Entonces, finalmente, también es ofensivo, porque ya, ¿cómo es un peruano? A veces he terminado respondiendo eso: «¿Entonces qué te parece a ti que es un peruano?». «No, es que son como más morenitos», no sé qué. (Rodrigo, primer encuentro, junio de 2014)

Las formas que adopta el extrañamiento se construyen en este complejo entramado de encuentro entre la configuración sociocultural de origen y la de 
destino, entramado que se encarna en el proceso de subjetivación de modos diversos. Por eso resulta tan importante el análisis situado de la experiencia del extrañamiento, como señala Ahmed (1999: 344, traducción propia): «El extrañamiento es siempre un alejamiento de un lugar y tiempo en particular». Por su parte, la encarnación diversa de este extrañamiento en los procesos de subjetivación se relaciona, entre otras cosas, con los diferentes niveles de reflexión que se generan en los sujetos a partir de estas experiencias. En ocasiones, el o la migrante se toman como objeto de análisis a partir de este extrañamiento de sí mismos que experimentan, otras veces, quizás las más comunes, se vive una incomodidad difusa, que no siempre logra articularse en el discurso, pero que de todas formas tiene implicancias en el proceso de subjetivación.

Laura (colombiana, productora audiovisual, 38 años, 6 viviendo en Santiago), por ejemplo, relata una escena en la que, aunque siendo colombiana, es «leída» como peruana o como ecuatoriana, y más específicamente otavaleña, ${ }^{10}$ por sus rasgos indígenas.

...lo que pasa es que asociaban mi color de piel a la nacionalidad peruana, y entonces todo el tiempo estaban diciendo... como la forma que me miraban era super despectiva (...). Imagínate que una vez iba yo a dictar un taller de video a unas personas trans... Entonces yo salí con mis maletas, estaban pesadas porque ahí llevo los equipos de video... Entonces tomé un taxi para ir a la terminal... Comienza a manejar [el taxista] y dice: « $\mathrm{i}$ para dónde va?». «A la terminal». «¿Y va para la playa a vender sus cosas?». Y yo: «¿Qué?, no, voy para otro lugar». «Ah, yo pensé que iba para la playa, porque en esta época todos sus paisanos van allá a vender sus cosas». Y yo: «¿Cuáles paisanos?». «Pues los ecuatorianos»... Entonces como el señor me ve morenita, cabello liso, lo único que podía llevar en esas maletas son sacos de lana para ir a vender a la playa. (Laura, primer encuentro, febrero de 2015)

En esta experiencia que narra Laura, el énfasis del extrañamiento está puesto en la dimensión étnico-racial, pero su relato también se refiere a la dimensión nacional del extrañamiento y a la de clase:

...y luego también cuando llego a Chile es la primera vez que comienzo a entender que soy colombiana, o sea, antes no era, pues sí, nací en Colombia, todos somos colombianos, no era nada, para mí no era una novedad ser colombiana, ni tampoco era consciente de lo que esa situación, claro, de cómo ser colombiana me situaba en un lugar específico al estar en Chile. No era lo mismo que si fuera chilena, no era lo mismo que si fuera argentina, no era lo mismo que si fuera peruana, no era lo mismo ser colombiana que ser otra cosa. Tampoco era lo mismo ser una colombiana que había llegado a estudiar, que había llegado en avión, que había llegado a vivir con una familia de chilenos, sí, ahí se juegan las diferencias, ¿̇ierto? Y aun así, dentro de algunos privile-

10. Esta asociación se vincula con la presencia en Chile de migración internacional ecuatoriana de la región de Otavalo, perteneciente a la etnia kichwa, principalmente dedicada a la venta de artesanías en puestos callejeros ambulantes. 
gios de mi forma de migrar, claro, me comienzo a encontrar con el estigma, de hipersexualización sobre las colombianas, el estigma sobre mi propio país, también los miedos que generamos los colombianos y las colombianas. (Laura, tercer encuentro, agosto de 2015)

En efecto, como Laura señala, en Chile la colombianidad, a grandes rasgos, supone encarnar en los cuerpos migrantes de ese origen las marcas de la violencia en general, de la narcoviolencia en particular, y las huellas de una sexualidad exaltada y exótica. En las mujeres colombianas que fueron parte de la muestra aparece esta vivencia en varios acontecimientos de su biografía migrante. Vanesa (colombiana, desocupada, 38 años, 1 año y medio viviendo en Santiago), por ejemplo, cuenta un acontecimiento que ocurrió el verano previo a nuestro primer encuentro. Habían decidido (ella y su pareja) viajar hacia el sur del país, hasta donde les alcanzara el dinero. En ese trayecto conocieron a una joven chilena y siguieron el viaje juntas, "echando dedo» con ella - solas no se atrevían a usar esta modalidad de acercamiento, porque no se acostumbra en Colombia. En un momento del viaje debieron continuar solas, y se animaron a hacerlo, así que las paró un camionero y se subieron:

...nos subimos al camión: "Hola, ustedes de dónde son». «De Colombia». Y empezó a platicarse él con otro [por teléfono celular], como decirle que le pasaba a una: «Mira, que es muy divertido, yo voy aquí contento porque voy con dos colombianas». Imagínate, el otro le decía: «No te lo puedo creer... pero por qué no me pasas una, con una colombiana». Imagínate... (Vanesa, primer encuentro, mayo de 2014)

Es solo uno de varios acontecimientos que emergen en el relato de las tres mujeres colombianas entrevistadas, y que van desde bromas más o menos sutiles hasta insinuaciones en locutorios, o incluso intentos de tocarlas en un ascensor. En estas situaciones de violencia, producto de un proceso de sexualización mediante el cual se construyen representaciones y se generan prácticas que les atribuyen, en función de su género y su nacionalidad, cierto tipo de actitudes y comportamientos frente a la sexualidad que se supone que atentarían contra una moralidad social imaginada, puede rastrearse el estrecho vínculo, o más que eso, la presencia indisociable, de las jerarquías de género y raza del régimen colonial, sustentadas en la preocupación por la pureza racial, y su continuidad en la construcción del imaginario nacional, a partir de un ordenamiento del mestizaje mediante el control de la sexualidad (Tijoux y Palominos, 2015). Este proceso en la formación nacional de alteridad está en la base de las imágenes que ligan a las mujeres colombianas a la figura de la puta, la caliente, la desinhibida, la curvilínea, la «robamaridos», imágenes de una feminidad libidinal (Pavez, 2016) que también genera una experiencia de extrañamiento, en este caso con un énfasis en la dimensión de género. Ese extrañamiento, tal como lo proponemos en este texto, excede una reacción de distanciamiento respecto a estereotipos y prejuicios a partir de los cuales pueden sentirse discriminados/as; refiere más bien a ese desdoblamiento de sí que los/las lleva a un descalce de su 
autoimagen, a partir de lo que ese otro les devuelve, y que puede derivar, como hemos insistido, en reflexiones más o menos elaboradas, o en incomodidades y malestares que, aunque de causa difusa, producen algún trastrocamiento en el proceso de subjetivación.

Los fragmentos de relatos presentados en este apartado muestran materializaciones del extrañamiento subjetivo que suponen, en general, nuevas constricciones biográficas, por las diversas formas de discriminación por las que se producen. Pero, a la par, el cruce de la frontera generó en estos casos ciertos movimientos en el proceso de subjetivación que nos hablan de la emergencia de algo nuevo. Esa emergencia está ligada a una suerte de liberación de la responsabilidad que implica el «ser parte» de ese todo imaginario al que sienten pertenecer al otro lado de esa frontera. Es esa ambigua posición de desanclaje la que habilita esa experiencia de liberación, menos relacionada con el hecho de estar en otro estado nación que con la sensación de no pertenencia plena (Stang, 2019), de extrañarse del aquí y el allá, de la posición intersticial a la que nos referíamos. En los entrevistados para el estudio del que surgieron estos relatos, esa experiencia liberadora se inscribe en la dimensión sexogenérica de sus biografías y, más específicamente, en sus procesos de subjetivación sexogenéricos no heteronormativos.

Mientras que las materializaciones constrictivas de las que hablamos antes se refieren fundamentalmente a un extrañamiento de sí mismo por el cruce de la frontera, la materialización liberadora remite sobre todo a un extrañamiento de los otros, aquellos otros conocidos, los otros familiares, que quedaron en el país de origen. En este caso, es un extrañarse más ligado a la idea de alejarse. Una de esas materializaciones es la puesta en discurso de la subjetivación sexogenérica no heteronormativa frente a la familia, la «salida del clóset» gracias a la distancia que permite poner el desplazamiento migratorio. Otra de esas materializaciones es la reconfiguración corporal, una suerte de recuperación del cuerpo propio, a partir de la apertura de las posibilidades de cortejo y demostración pública de afecto, algo que les estaba restringido en el lugar de origen, por esa cercanía de los conocidos y lo conocido (Stang, 2019). ${ }^{11}$

En estas corrosiones de fronteras que se habían inscrito en la dimensión sexogenérica de sus vidas (esta que se establece entre hombre y mujer, o entre homo y heterosexualidad), hay un reposicionamiento como sujetos de enunciación desde donde decirse y hacerse, un extrañamiento que se traduce en agencia, y que una de las entrevistadas explica con fuerza metafórica. «[C]uando regresas — porque la idea del regreso siempre está, como señala Sayad—, no vas a ser la misma persona, de alguna forma te abortaste, abortaste la figura que estabas vendiendo allá", dice Daniela. Si bien esta es una experiencia común para el migrante que retorna — como sostiene Schütz (2012), el/la que vuelve

11. Dado que no es el tema central de este artículo y teniendo en cuenta las limitaciones de espacio, no se abordan en detalle ni se ejemplifican las experiencias liberadoras en estos procesos de subjetivación a partir del cruce de la frontera. Para mayor detalle de este punto, puede consultarse Stang (2019). 
al hogar nunca es el/la mismo/a que lo abandonó-, en este caso ese cambio se amplifica, en la medida en que, antes de su marcha, ese/a que partió estaba en el clóset, es decir, no era del todo para esos otros lo mismo que para sí. En otro encuentro, Daniela se refiere al modo en que se ha sentido interpelada por la experiencia migratoria, a través de una necesidad permanente de reflexión sobre sus nuevas vivencias, la actitud epistemológica sobre sí misma: «[E]so creo que tiene mucho que ver con el viaje, lo que hablábamos, no hay forma en que tú te aplaces [postergues]. No hay compromisos a través de los cuales te puedas aplazar, tú, siempre estás tú, pariéndote todo el rato» (Daniela, segundo encuentro, mayo de 2014). La apelación a las metáforas del aborto y el parto, de la muerte y el nacimiento — en rigor, renacimiento—, no son casuales, ya que son dos imágenes muy poderosas respecto a la experiencia del extrañamiento y sus consecuencias en las trayectorias de subjetivación.

\section{Conclusiones}

El recorrido propuesto en este artículo, alimentado por reflexiones teóricas, metodológicas, y por evidencia empírica, nos conduce a pensar la experiencia de extrañamiento subjetivo en estos procesos migratorios internacionales - de carácter sur-sur, dentro de América Latina- como un movimiento de doble faz, inextricablemente articulado, por el que el migrante se vincula no solo a la alteridad encarnada en el otro (el otro de la lengua, del género, de la nación, etcétera) que lo refleja (en el que el migrante se mira a sí mismo), sino a su alteridad «interior». Ese movimiento de doble faz arranca de la experiencia de ser traducido por el otro (en otros códigos) y ubicado en una nueva escala social (jerarquizada, por ejemplo, por posiciones de extranjeridad, nacionalidad, clase, género, etnia, «raza», lengua, etcétera). Postulamos que, en ocasiones, aquella imagen, aquella traducción, que «siempre es una interpretación y, como tal, opera como modo de resignificación» (Brah, 1996: 279), descalza al migrante, sobre todo en las etapas iniciales del trayecto migratorio, respecto a la forma en que se entendía a sí mismo, una suerte de desidentificación y distancia que, como hemos dicho, se acompaña de una reacción de extrañeza (Sayad, 1999).

Con relación a la noción de extrañeza, tomamos las elaboraciones sobre la posición del etnógrafo como una actitud de sorpresa con lo que no encaja con nuestra perspectiva y que busca volver familiar lo exótico, lo que implica un descentramiento, es decir, una distancia respecto a sí mismo. En cuanto a la extrañeza de la propia alteridad, tomamos la concepción freudiana de la inquietante extrañeza y de la elaboración de Kristeva (1988) en torno a la idea de «extranjeros a nosotros mismos». Sobre esta doble faz de la relación con la alteridad (respecto al otro y respecto a sí mismo), hemos planteado que se trata de una relación de continuidad, de modo que lo que impacta en uno resuena o implica en el otro.

A su vez, siguiendo a Sayad (1991), hemos situado el cruce de fronteras como un paso en que el sujeto «nace» como migrante y en el que se advierte el arbitrario cultural, es decir, la pérdida de su carácter «natural», como lo dado y 
no problemático que tenía hasta ese momento. Es en el cruce de fronteras —en su sentido amplio, es decir, no acotado a la idea de límite geopolítico, y pensando el cruce como un proceso, y no como un momento- donde el encuentro con la alteridad se pone en juego, como espacio de traducción (Maffia, 2007) que se vincula a una concepción intersticial de la frontera (Stang, 2020), es decir, a un estar situado en el lugar ambiguo del entre, el entremedio, y de la no pertenencia plena. En esta concepción, la pertenencia nacional única y total es puesta en tensión por las vidas migrantes, sus identificaciones parciales, discontinuas, en ocasiones contradictorias, y multisituadas.

Entonces, nos hemos preguntado por los impactos subjetivos que imprime en el migrante esta experiencia y cómo se las arregla con aquello. A través de los relatos, hemos analizado cómo el descalce respecto a la imagen que al migrante le viene del otro hace tambalear algunas certezas identitarias, lo que abre un espacio respecto a lo propio y pone en tensión el límite con lo ajeno. Decimos que esto conduce a un proceso de subjetivación, en la medida en que el sujeto se piensa a sí mismo, se toma como objeto de reflexión, ya que, como señala Brah, «las modalidades de enunciación, de las identidades, posicionalidades y puntos de vista están a la vez dentro y fuera» (1996: 242).

Las nociones de pliegue y de intersticio, a las que hemos apelado en este texto, dan cuenta de este proceso: el pliegue del afuera «incorpora sin totalizar» (Rose, 1996: 236), es decir, no termina de cerrar definitivamente el adentro del afuera; la posición intersticial de la frontera, así, alude a un estar entre, ni definitivamente en un lugar, ni definitivamente en otro. Esa posición inestable de sujeto, en construcción multirreferenciada, logra aprehender en alguna forma esa experiencia biográfica de la migración, y su huella en el proceso de subjetivación.

Los relatos nos muestran algunas formas — situadas en procesos migratorios (en general no forzados, ni temporales) de carácter sur-sur, dentro de América Latina- en que los sujetos migrantes se las arreglan con la experiencia de descalce y extrañamiento inicial para estabilizar una cierta imagen identitaria que despliegan de modo situacional y estratégico, con la que, sin embargo, no necesariamente se encuentran del todo identificados/as. Nos hablan de la experimentación de constricciones, inquietudes y malestares, pero también de la apertura de nuevas posibilidades, de nuevas posiciones enunciativas para sí y frente a los otros, en las que es preciso poner atención con la dedicación de esfuerzos investigativos.

\section{Referencias bibliográficas}

Ahmed, Sara (1999). «Home and away. Narratives of migration and estrangement». International Journal of Cultural Studies, 2 (3), 329-347. <https://doi.org/10.1177/136787799900200303>

Althusser, Louis (1970). Ideología y aparatos ideológicos del Estado. México: Grijalbo, 1977.

Arfuch, Leonor (2002). El espacio biográfico. Dilemas de la subjetividad contemporánea. Buenos Aires: Fondo de Cultura Económica. 
Bertaux, Daniel (1997). Los relatos de vida. Perspectiva etnosociológica. Barcelona: Bellaterra, 2005.

Bнавна, Homi (2010). «DisemiNación. Tiempo, narrativa y los márgenes de la nación moderna». En: BнAвнA, Homi (comp.). Nación y narración. Buenos Aires: Siglo XXI.

- (2011). El lugar de la cultura. Buenos Aires: Manantial.

Blasco, Josep M. (1993). «El estadio del espejo. Introducción a la teoría del yo en Lacan». Presentado en conferencias del ciclo «Psicoanálisis a la vista». Escuela de Psicoanálisis de Ibiza.

Bleichman, Silvia (2010). Desmantelamiento de la subjetividad. Estallido del yo. Buenos Aires: Topía.

Bonhomme, Macarena (2013). «Cultura material y migrantes peruanos en Chile: un proceso de integración desde el hogar». Polis, Revista Latinoamericana, 12 (35), 63-84. <https://doi.org/10.4067/S0718-65682013000200004>

Bornhauser, Niklas (2012). «Extranjera subjetividad. La experiencia de la otredad en la senda interpretativa freudiana». Actuel Marx/Intervenciones, 12, 91-104. Recuperado de <http://bibliotecas.uchile.cl/documentos/20161017-0237709821.pdf>.

Brah, Avtar (1996). Cartografias de la diáspora. Identidades en cuestión. Buenos Aires: Traficantes de Sueños, 2011.

Caggiano, Sergio (2003). «Fronteras múltiples: reconfiguración de ejes identitarios en migraciones contemporáneas a la Argentina». Cuadernos del IDES, (1). Recuperado de <http://biblioteca.clacso.edu.ar/gsdl/collect/ar/ar025/index/assoc/D4320.dir/ cuaderno1_caggiano.pdf $>$.

Certeau, Michel de (1980). La invención de lo cotidiano. Artes de hacer. México: Universidad Iberoamericana / Instituto Tecnológico y de Estudios Superiores de Occidente, 1996.

Checa Olmos, Francisco (2003). «Inmigración y diversidad en España. Una aproximación desde el extrañamiento cultural». Convergencia. Revista de Ciencias Sociales, 10 (33), 139-175.

$<$ https://convergencia.uaemex.mx/article/view/1586>.

Checa Olmos, Francisco; Arjona Garrido, Ángeles y Checa Olmos, Juan Carlos (2007). «El extrañamiento cultural en espacios migratorios. La juventud andaluza ante el reto de la multiculturalidad». Migraciones Internacionales, 4 (1), 111-140. Recuperado de <http://www.scielo.org.mx/scielo.php?script=sci_arttext\&pid $=$ S166589062007000100005>.

Deleuze, Gilles (1986). La subjetivación. Curso sobre Foucault. Buenos Aires: Cactus, 2015.

Elías, Norbert (1977). El proceso de la civilización. Investigaciones sociogenéticas y psicogenéticas. México: Fondo de Cultura Económica, 2009.

Eribon, Didier (1999). Reflexiones sobre la cuestión gay. Barcelona: Anagrama, 2001.

Fannon, Franz (2015). Piel negra, máscaras blancas. Barcelona: Editorial Akal.

Freud, Sigmund (1901). Psicopatología de la vida cotidiana. Obras completas, vi. Madrid: Amorrortu, 1979.

- (1919). Lo ominoso. Obras completas, Xvir. Madrid: Amorrortu, 1979.

- (1921). Psicología de las masas y análisis del yo. Obras completas, XviII. Madrid: Amorrortu, 1979.

Grimson, Alejandro (2000). «El puente que separó dos orillas. Notas para una crítica del esencialismo de la hermandad». En: Grimson, Alejandro. Fronteras, naciones e identidades. La periferia como centro. Buenos Aires: Ciccus-La Crujía. 
- (2012). Los límites de la cultura. Crítica de las teorías de la identidad. Buenos Aires: Siglo XXI.

Gutiérrez Rodríguez, Encarna (2005). «Anhelos diaspóricos y la pequeña libertad: sexualidad, migración y precariedad». En: Romero Bachiller, Carmen; García Dauder, Silvia y Bargueiras Martínez, Carlos (eds.). El eje del mal es heterosexual. Figuraciones, movimientos y prácticas feministas queer. Madrid: Traficantes de Sueños.

Hall, Stuart (1996). "¿Quién necesita “identidad”?». En: Hall, Stuart y GaY, Paul du (eds.). Cuestiones de identidad cultural. Buenos Aires: Amorrortu, 2003.

Izquierdo Escribano, Antonio (2000). «El proyecto migratorio de los indocumentados según género». Papers, 60, 225-240.

$<\mathrm{https} / / /$ doi.org/10.5565/rev/papers/v60n0.1040>

Kristeva, Julia (1988). Extranjeros para nosotros mismos. Barcelona: Plaza y Janés, 1991.

LACAN, Jacques (1966). «El estadio del espejo como formador de la función del yo [je] tal como se nos revela en la experiencia psicoanalítica». En: LACAN, Jacques. Escritos I. México, DF: Siglo Xxi, 2009.

LaClau, Ernesto (1993). Nuevas reflexiones sobre la revolución de nuestro tiempo. Buenos Aires: Nueva Visión.

Lara, Antonia (2019). «Subjetividades en dislocación: cuerpo y acento en los desplazamientos migratorios». Simbiótica, 6 (1), 232-255.

<https://doi.org/10.47456/simbitica.v6i1.27205>

Lins, Gustavo (2004). «Descotidianizar. Extrañamiento y conciencia práctica, un ensayo sobre la perspectiva antropológica». En: Borvin, Mauricio et al. (eds.). Constructores de otredad. Una introducción a la Antropología Social y Cultural. Buenos Aires: Antropofagia.

Maffía, Diana (2007). Los cuerpos como frontera. Mimeo.

Margulis, Mario (1999). "La "racialización" de las relaciones de clase». En: MARGULis, Mario; URResti, Marcelo et al. La segregación negada: cultura y discriminación social. Buenos Aires: Biblos.

Olmos, Antonia (2016). «Algunas reflexiones sobre la etnografía escolar: holismo, extrañamiento y diversidad cultural». Investigación en la Escuela, 23, 1-16. <https://doi.org/10.12795/IE.2016.i89.01>

PAvez, Jorge (2016). «Afecciones afrocolombianas. Transnacionalización y racialización del mercado del sexo en las ciudades mineras del norte de Chile». Latin American Research Review, 51 (2), 24-45. <https://doi.org/10.1353/lar.2016.0021>

Piscitelli, Adriana (2008). «Interseccionalidades, categorias de articulação e experiências de migrantes brasileiras». Sociedade e Cultura (11), 263-274. $<$ https://doi.org/10.5216/sec.v11i2.5247>

Rancière, Jaques (1995) El Desacuerdo. Política y filosofía. Buenos Aires: Nueva Visión, 1996.

Rose, Nikolas (1996). «Identidad, genealogía, historia». En: Hall, Stuart y GaY, Paul du (eds.). Cuestiones de identidad cultural. Buenos Aires: Amorrortu, 2003.

Sabsay, Liliana (2011). «El sujeto político de la diversidad». En: SABSAY, L. (2011). Fronteras sexuales. Espacio urbano, cuerpos y ciudadanía. Buenos Aires: Paidós.

SAYAD, Abdelmalek (1991). A imigracão ou os paradoxos da alteridade. São Paulo: Edusp, 1998.

- (1999). La doble ausencia. De las ilusiones de emigrado a los padecimientos del inmigrado. Barcelona: Anthropos, 2010. 
Schütz, Alfred (2001). Las estructuras del mundo de la vida. Buenos Aires: Amorrortu. - (2012). «La vuelta al hogar». En: Simmel, G. et al. (2012). El extranjero. Sociología del extraño. Madrid: Sequitur.

- (2012). «El forastero. Ensayo de psicología social». En: Simmel, G. et al. (2012). El extranjero. Sociología del extraño. Madrid: Sequitur.

Segato, Rita (2007). La Nación y sus Otros. Raza, etnicidad y diversidad religiosa en tiempo de Políticas de Identidad. Buenos Aires: Prometeo.

Simmel, Georg (2012). "El extranjero». En: Simmel, G. et al. (2012) El extranjero. Sociología del extraño. Madrid: Sequitur.

StAng, Fernanda (2018). Fronteras, sexualidades y procesos de subjetivación. Migrantes LGTBIQ colombianos y peruanos en Santiago de Chile. Tesis para optar al grado de Doctora en Estudios Sociales de América Latina. Córdoba: Universidad Nacional de Córdoba.

- (2019). «La frontera como hito biográfico. Migración, diversidad sexual y extrañamiento en procesos migratorios Sur-Sur». Ensambles, 5 (10), 18-35.

- (2020). «La frontera como intersticio. Reflexiones en torno a la violencia epistémica de las fronterizaciones». REMHU, Revista Interdisciplinar da Mobilidade Humana, 28 (59), 13-28.

<https://doi.org/10.1590/1980-85852503880005902>

Stefoni, Carolina y Bonhomme, Macarena (2014). "Una vida en Chile y seguir siendo extranjeros». Si Somos Americanos, 14 (2), 81-101. <https://doi.org/10.4067/S0719-09482014000200004>

Strejilevich, Nora y Filc, J. (2015). «Genres of the Real». En: Rodríguez, Ileana y Szurmuk, Mónica (eds.). The Cambridge History of Latin American Women's Literature. Cambridge: Cambridge University Press. <https://doi.org/10.1017/CHO9781316050859.030>

Tijoux, María Emilia y Palominos, Simón (2015). «Aproximaciones teóricas para el estudio de procesos de racialización y sexualización en los fenómenos migratorios de Chile». Polis. Revista Latinoamericana, 14 (42), 247-275. <https://doi.org/10.4067/S0718-65682015000300012>

URBALEJO, Lorenia (2019). «Hacerse joven en el contexto migrante y ser joven migrante: diferenciaciones y conexiones identificatorias». En: BACA TAVIRA, Norma; BAUtista León, Andrea y Mojica Madrigal, Ariel (coords.). Jóvenes y migraciones. Ciudad de México: Gedisa.

Velasco, Laura y Gianturco, Giovanna (2012). «Migración internacional y biografías multiespaciales: una reflexión metodológica». En: Métodos cualitativos y su aplicación empirica. Por los caminos de la investigación sobre migración internacional. México, DF: Instituto de Investigaciones Sociales, UNAM y El Colegio de la Frontera Norte.

Velasco, Honorio y Díaz de la Rada, Ángel (1997). La lógica de la investigación etnográfica. Madrid: Trotta, 2006.

VIÑar, Marcelo (comp.) (1998). ¿Semejante o enemigo?: entre la tolerancia y la exclusión. Montevideo: Trilce.

Viveiro de Castro, Eduardo (2002). Inconstancia da alma salvagem. São Paulo: Cosac \& Naify. 